\title{
Hemophagocytic Syndrome as an Initial Presentation of Systemic Lupus Erythematosus: A Case Report
}

Mohammed AlSheef ${ }^{1}$, Abdul Rehman Z. Zaidi ${ }^{2}$, AbdulAziz A. AlAtmi ${ }^{2}$, Lina H. AlSharif ${ }^{3}$, Arshad Mian ${ }^{2}$

1. Medicine, King Fahad Medical City, Riyadh, SAU 2. Internal Medicine, King Fahad Medical City, Riyadh, SAU 3. Emergency Medicine, King Fahad Medical City, Riyadh, SAU

Corresponding author: Mohammed AlSheef, malsheef@kfmc.med.sa

\begin{abstract}
Hemophagocytic syndrome (HPS) is an uncommon potentially life-threatening hematological disorder characterized by fever, pancytopenia, lymphadenopathy, and activation of macrophages, which can be associated with various diseases. HPS brings significant diagnostic and therapeutic challenges, especially if it is the presenting manifestation of an autoimmune disorder, which is uncommon. We present a case of hemophagocytic syndrome as an initial presentation of systemic lupus erythematosus (SLE). We also highlight this rare initial presentation of SLE where initial antinuclear antibody and extractable nuclear antigen tests were negative. To the best of our knowledge, this is the first case of isolated HPS evolving into SLE in the Middle East.
\end{abstract}

Categories: Internal Medicine, Rheumatology

Keywords: hemophagocytic syndrome, systemic lupus erythematosus, middle east, sle, saudi arabia, hps

\section{Introduction}

Hemophagocytic syndrome (HPS) is an uncommon hematological disorder characterized by hyperinflammatory response caused by abnormal activation of the immune system leading to an increase of cytokines in the blood [1]. HPS is a potentially life-threatening condition, which is usually manifested by fever, pancytopenia, lymphadenopathy, hepatosplenomegaly, elevated ferritin, and high triglycerides [2]. HPS has two types, primary (hereditary) and secondary (reactive). The secondary type is often associated with underlying disorders such as infections, malignancies, and autoimmune disorders, including systemic lupus erythematosus (SLE) [3]. When SLE is the fundamental cause of reactive hemophagocytosis, it is described as acute lupus hemophagocytic syndrome (ALHS) [4].

We report a rare presentation of SLE, which initially presented as HPS.

Received 07/22/2019

Review began 07/27/2019 Review ended 07/27/2019 Published 07/29/2019

\section{() Copyright 2019}

AISheef et al. This is an open access article distributed under the terms of the Creative Commons Attribution License CC-BY 3.0., which permits unrestricted use, distribution, and reproduction in any medium, provided the original author and source are credited.

\section{Case Presentation}

A 24-year-old Saudi woman, not known to have any medical illness, presented to the emergency room with a history of high-grade fever for two weeks. She denied any history of joint pain, skin rash, oral ulcers, night sweats, headache, seizure, and weight loss. There was no family history of connective tissue diseases or malignancies.

On examination, a palpable left posterior cervical lymph node $(1 \times 2 \mathrm{~cm})$ was found. There was no organomegaly and no signs of active synovitis or skin rash. Laboratory examination revealed pancytopenia, coagulopathy and elevated liver function tests. Ferritin level was very high (5199 ug/L), antinuclear antibody test (ANA), and extractable nuclear antigen test (ENA) were initially negative. Peripheral blood film showed microcytic hypochromic anemia with $4 \%$ atypical lymphocytes. Erythrocyte sedimentation rate (ESR) was elevated $(79 \mathrm{~mm} / \mathrm{h})$. C-reactive protein (CRP) was normal $(3.9 \mathrm{mg} / \mathrm{L})$. The culture was negative for fungi and bacteria. Serology was negative for cytomegalovirus (CMV), Epstein-Barr virus (EBV), hepatitis A virus (HAV), hepatitis B virus (HBV), hepatitis $\mathrm{C}$ virus (HCV) and human immunodeficiency virus (HIV). Computerized tomography (CT) scan showed multiple enlarged lymph nodes in both sides of the neck, supraclavicular, axillary, mediastinal, retroperitoneal, and pelvic area (Figures 1, 2). Bone marrow biopsy showed proliferation of macrophages with significant hemophagocytosis (Figure 3). Flow cytometry was negative for myeloproliferative and lymphoproliferative disorders. 


\section{Cureus}

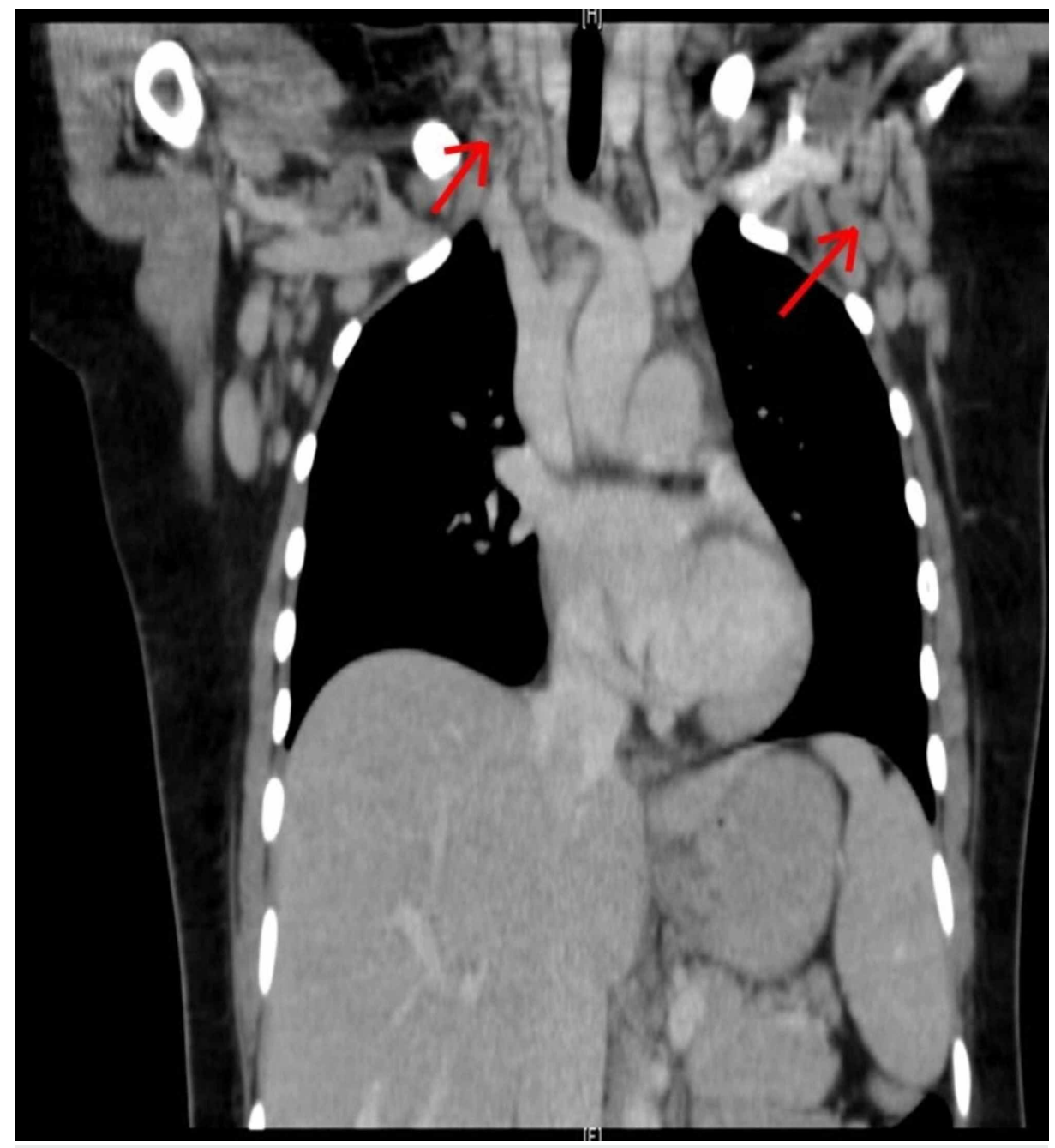

FIGURE 1: Coronal CT scan of the chest showed pathologically enlarged cervical, supraclavicular, axillary and mediastinal lymph nodes.

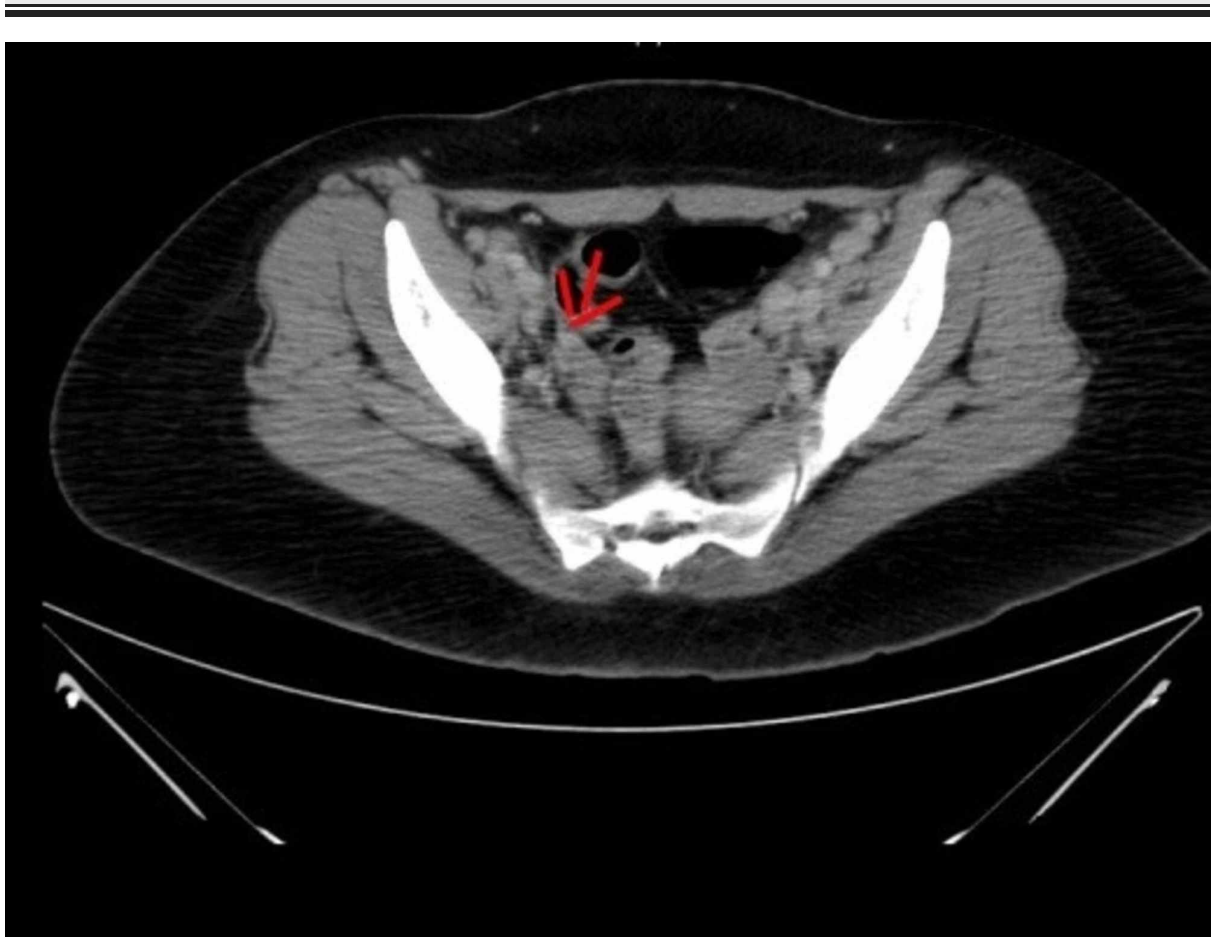




\section{Cureus}

FIGURE 2: Axial CT scan of the pelvis showed pathologically enlarged inguinal lymph nodes.

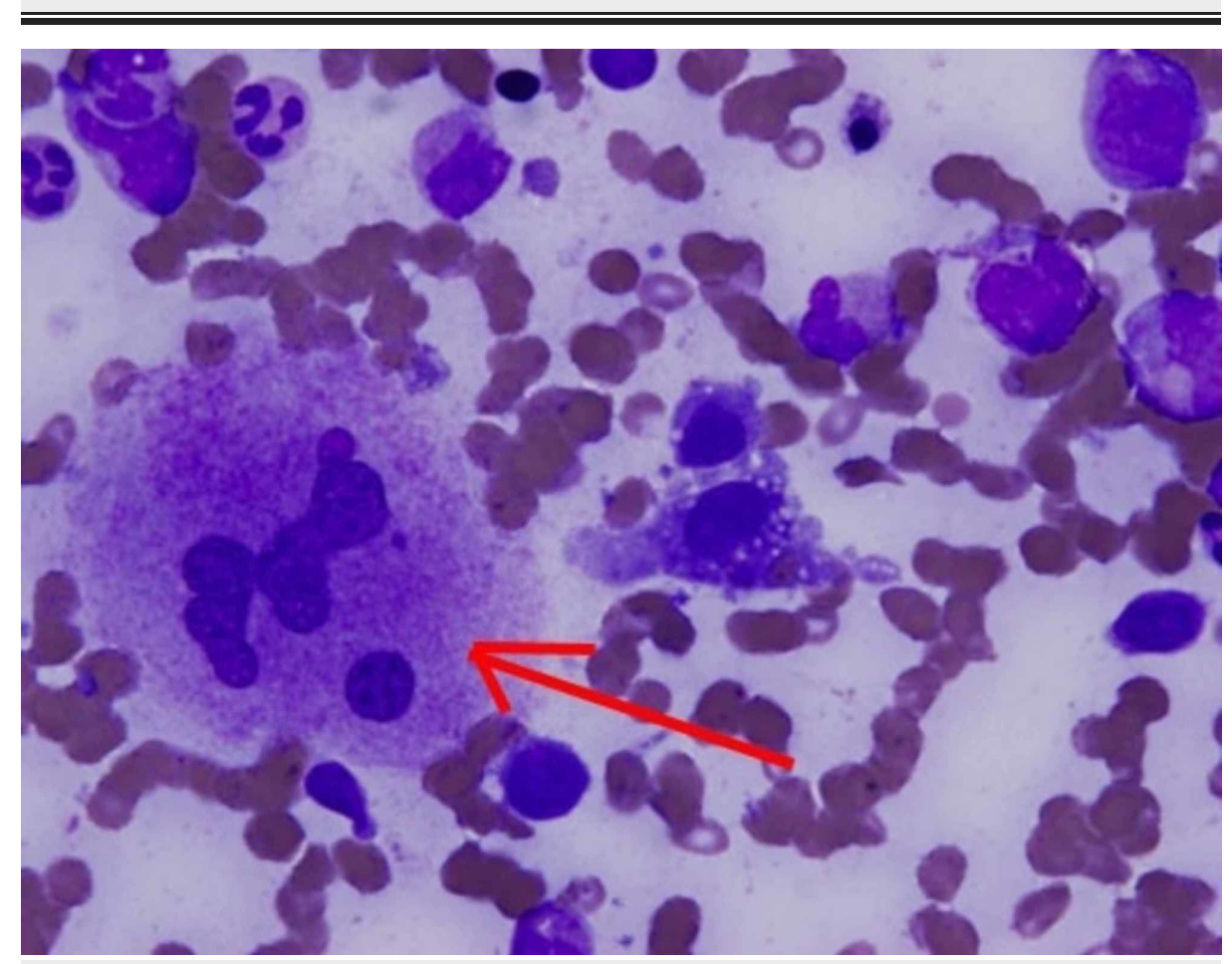

FIGURE 3: Bone marrow biopsy showed proliferation of macrophages with significant hemophagocytosis.

After three weeks of extensive workup, no secondary cause for HPS could be identified (Table 1). Lymph node biopsy was refused by the patient. She was treated with general supportive measures including broadspectrum antibiotics, blood products, and granulocyte colony-stimulating factor (GCSF) with significant clinical improvement. Five months later, on follow-up, she developed arthralgias, alopecia, and a malar rash. Repeated ANA/ENA screen was strongly positive. A diagnosis of SLE was made as per the American College of Rheumatology (ACR) criteria. Subsequently, she was started on prednisone and hydroxychloroquine and improved dramatically. 


\section{Cureus}

\begin{tabular}{|c|c|c|c|}
\hline Test & Value at Initial Presentation & Value at Follow-up Visits & Reference Range \\
\hline WBCs & $0.92 \times 10^{9} / \mathrm{L}$ & $3.75 \times 10^{9} / \mathrm{L}$ & $4-11 \times 10^{9} / L$ \\
\hline ANC & $0.19 \times 10^{9} / L$ & $1.8 \times 10^{9} / \mathrm{L}$ & $2.6-7.5 \times 10^{9} / \mathrm{L}$ \\
\hline $\mathrm{Hb}$ & $10.6 \mathrm{~g} / \mathrm{dl}$ & $13.1 \mathrm{~g} / \mathrm{dl}$ & $12-16 \mathrm{~g} / \mathrm{dl}$ \\
\hline Platelets & $95 \times 10^{9} / \mathrm{L}$ & $164 \times 10^{9} / L$ & $140-450 \times 10^{9} / \mathrm{L}$ \\
\hline Ferritin & $5199 \mathrm{mg} / \mathrm{L}$ & $148 \mathrm{mg} / \mathrm{L}$ & $13-150 \mathrm{mg} / \mathrm{L}$ \\
\hline APTT & 70.2 sec. & $36 \mathrm{sec}$. & $26-40 \mathrm{sec}$. \\
\hline ANA & Negative (twice) & Positive & \\
\hline Anti-ds DNA & Negative & Positive (240) & \\
\hline AST & $934 \mathrm{U} / \mathrm{L}$ & $35 \mathrm{U} / \mathrm{L}$ & 15-37 U/L \\
\hline ALT & $194 \mathrm{U} / \mathrm{L}$ & $34 \mathrm{U} / \mathrm{L}$ & $30-66 \mathrm{U} / \mathrm{L}$ \\
\hline ALP & $642 \mathrm{U} / \mathrm{L}$ & $71 \mathrm{U} / \mathrm{L}$ & $50-136 \mathrm{U} / \mathrm{L}$ \\
\hline Gamma GT & $1669 \mathrm{U} / \mathrm{L}$ & $20 \mathrm{U} / \mathrm{L}$ & 7-32 U/L \\
\hline LDH & 4207 U/L & $220 \mathrm{U} / \mathrm{L}$ & 81-234 U/L \\
\hline Triglycerides & $2.79 \mathrm{mmol} / \mathrm{L}$ & $1.59 \mathrm{mmol} / \mathrm{L}$ & $0-1.7 \mathrm{mmol} / \mathrm{L}$ \\
\hline
\end{tabular}

\section{TABLE 1: A comparison between blood tests during patient's initial presentation and follow-up}

visits.

WBCs: White Blood Cells; ANC: Absolute Neutrophil Count; Hb: Hemoglobin; APTT: Activated Partial Thromboplastin Time; ANA: Antinuclear Antibody; Anti-ds DNA: Anti-double stranded DNA; AST: Aspartate Aminotransferase; ALT: Alanine Aminotransferase; ALP: Alkaline Phosphatase; LDH: Lactate Dehydrogenase.

\section{Discussion}

In our case, all the clinical findings and laboratory results indicate the diagnosis of HPS initially without any provocative disease. Five months later, on follow-up, she developed arthralgias, alopecia, and a malar rash. Repeated ANA/ENA screen was strongly positive. According to the previous presentation, HPS preceded the evolution of full-blown SLE. In contrast, in 2011, in France, Elqatni et al. reported a case of abdominal pain that was associated with acute pancreatitis related to SLE, which was identified seven months before HPS [5]. However, in Japan, in the year 2012, Miura et al. reported a case of lupus nephritis complicated with nephrotic syndrome after extensive treatment and the disease had been controlled. In addition, their patient suffered from EBV that was associated with HPS and treated with chemotherapy and achieved complete remission [6]. Another case was reported in 2002 by Moriguchi et al. in Japan, who presented in 1998 with a diagnosis of HPS and SLE with increasing interleukin (IL)- 6 and IL-1 beta; this case indicated that high cytokines could be present with HPS [7]. A similar presentation was found in a case reported in 2008 by Taki et al. in Japan, who presented as a case of SLE that presented with HPS as initial presentation [3]. Also, in 2007, Yeap et al. in Taiwan reported a case of a female that presented initially with HPS as the initial presentation of SLE [8]. This illustrates that HPS can precede, coincide, or follow the evolution of full-blown SLE, which is exceedingly rare but a potentially fatal disorder. In the right clinical setting, patients with HPS without a clear secondary cause should be followed for the development of symptoms and signs of secondary HPS such as SLE.

\section{Conclusions}

In conclusion, to the best of our knowledge, this is the first reported case in the Middle East of an adult presenting as HPS that later evolved to SLE. Furthermore, we should consider following patients with isolated HPS and anticipate for signs and symptoms of secondary HPS, such as SLE. This also calls attention to the importance of vigilance and the need for robust follow-up of patients presenting with HPS, even when the patient does not primarily have a clinical picture of SLE.

\section{Additional Information}

Disclosures 
Human subjects: Consent was obtained by all participants in this study. King Fahad Medical City IRB issued approval 19-169. Patient consent was taken for this case report and IRB exemption was taken from our institution. Conflicts of interest: In compliance with the ICMJE uniform disclosure form, all authors declare the following: Payment/services info: All authors have declared that no financial support was received from any organization for the submitted work. Financial relationships: All authors have declared that they have no financial relationships at present or within the previous three years with any organizations that might have an interest in the submitted work. Other relationships: All authors have declared that there are no other relationships or activities that could appear to have influenced the submitted work.

\section{Acknowledgements}

We are grateful to Dr. Aziza Al-Suwaied (Pathology consultant at King Fahad Medical City) and Dr. Khalid Al-Dossary (Radiology consultant at King Fahad Medical City) for their kind help and cooperation in obtaining the patient's figures.

\section{References}

1. Ren W, Zhong Z, Zhao X, et al.: Primary testicular non-Hodgkin's lymphoma associated with hemophagocytic syndrome: case report and review of the literature. Oncol Lett. 2012, 4:59-62. 10.3892/ol.2012.701

2. Imashuku S: Differential diagnosis of hemophagocytic syndrome: underlying disorders and selection of the most effective treatment. Int J Hematol. 1997, 66:135-151. 10.1016/S0925-5710(97)00584-7

3. Taki H, Shinoda K, Hounoki H, Ogawa R, Hayashi R, Sugiyama E, Tobe K: Presenting manifestations of hemophagocytic syndrome in a male patient with systemic lupus erythematosus. Rheumatol Int. 2010, 30:387-388. 10.1007/s00296-009-0932-5

4. Wong K-f, Hui P-k, Chan JKC, Chan Y-w, Ha S-y: The acute lupus hemophagocytic syndrome. Ann Intern Med. 1991, 114:387-390. 10.7326/0003-4819-114-5-387

5. Elqatni M, Mekouar F, Sekkach Y, et al.: Haemophagocytic syndrome as a complication of acute pancreatitis during systemic lupus erythematosus. (Article in French). Ann Dermatol Venereol. 2012, 139:46-49. 10.1016/j.annder.2011.10.398

6. Miura S, Takeda K, Muto Y, et al.: Repeated Epstein-Barr virus-associated hemophagocytic syndrome in a lupus nephritis patient. Clin Nephrol. 2012, 77:71-74. 10.5414/cn106937

7. Moriguchi N, Sato W, Miyata H, Yoshioka K: Systemic lupus erythematosus with bilateral salivary gland swelling and clouding of consciousness accompanied by hemophagocytic syndrome--a study of serial determination of serum cytokines. (Article in Japanese). Rinsho Ketsueki. 2002, 43:931-936.

8. Yeap ST, Sheen JM, Kuo HC, Hwang KP, Yang KD, Yu HR: Macrophage activation syndrome as initial presentation of systemic lupus erythematosus. Pediatr Neonatol. 2008, 49:39-42. 10.1016/s18759572(08)60010-8 